\title{
The Effect of Movies on Inference the Meanings of Vocabulary: Turkish L2 Learners of English
}

\author{
Tuğba AYDIN YILDIZ \\ Lecturer, Dr. \\ The School of Foreign Languages \& Kdz. Ereğli Meslek Yüksekokulu \\ Zonguldak Bülent Ecevit University \\ Karadeniz Ereğli Zonguldak \\ Turkey
}

\begin{abstract}
The present study aimed to investigate the potential effect of inferring the meaning from visual context in the acquisition of the vocabulary with second language adult learners of English (L2 learners). Firstly, due to being interesting, rich in terms of vocabulary and not boring, an English movie "The King's Speech" was chosen. An offline vocabulary test was prepared in order to decide which words (from the mentioned movie) were unknown by the subjects, then including 20experimental sentences and 40 fillers. After that, the same vocabularies were presented in the context as "The King's Speech" movie with 6 episodes was screened on the projector in the classroom, and each of them was almost 20 minutes. What is expected from the L2 learners is to infer the meaning of the unknown vocabularies most correctly in the visual and audial context. After six session of watching the movie, all participants were requested to answer the multiple-choice vocabulary post-test. The results have showed that most of the participants are better at inferring the meanings in questions after visual context sessions.
\end{abstract}

Keywords: Acquisition of vocabulary, L2 learners, inferring, context.

\section{Introduction}

Without vocabulary knowledge, a basic competence cannot be existed in communication (Seal, 1991). In the study of Richards (1976), the definition of knowing a word means to know the frequency, syntactic, semantic and morphological features, derivations, different forms, and associations of the word. Additionally, Nation (1990) described knowing a word as knowing the spelling, pronunciation, collocations, and appropriateness of the word. Vocabulary acquisition is one of the biggest difficulties second language learners (L2 learners) encounter while processing. In order to lessen the burden on the L2 learners, vocabulary learning could be managed through informing the learners about strategies, using context and to what extent the content of a word expands. Words are the building stones of a language since they mark the objects, actions, ideas without which people cannot conduct the intended meaning (Ghazal, 2007). For a very long time, different variety of approaches, strategies, tests and practices have been investigated to teach vocabulary (Hatch \& Brown, 1995). Many studies have examined the issue from different perspectives such as; teaching vocabulary strategy in the field is of great importance at least as memorizing (Morin \& Goebel, 2001), during the process of being a self-directed learner, one should gain confidence, contribute and be an expert of learning responsibility (Oxford, 1990).The L2 learner should interpret, learn, take responsibility, and train by using strategies in technological environment more confidently. With the development of technology, the audial and visual authentic materials attributed the process of learning vocabulary in the second language (Canning-Wilson, 2000;Ryan, 1998; Weyer, 1999).

Overall, by using technology, the present paper aims to examine the role of movies on learning the vocabulary since the movies have both audial and visual materials as well as context without which the process become less meaningful. To this end, a brief account of general learning strategies, inferring strategies, context, and visual and audial material usage in vocabulary learning will be initially introduced. Then, the methodology of the study, the results and the discussion part will be mentioned. 


\section{Literature Review on Vocabulary Learning Strategies}

As Ghazal (2007) mentioned before, in the study of Gu and Johnson (1996), the vocabulary learning strategies for L2 learners are sorted as; metacognitive strategies in which the L2 learner should rank the words and be conscious in determining the true meaning of the words, cognitive strategies in which the L2 learner predict the linguistic knowledge, use the dictionaries effectively, memory strategies in which the learner should classify the words into rehearsal and encoding strategies such as grouping the words according to their associations or morphological features, and activation strategies in which the learners should be capable of using the newly-learned knowledge into various contexts. A revision of the study of Oxford (1990), Schmitt (1997) asserts the vocabulary learning strategies under five categories such as determination (trying to learn the meaning of a word by inferring from the context or by guessing), social (consolidating or using social and communicative competence to reach the meaning of a word), memory (generally known as mnemonics, using previous knowledge), cognitive (repetition and using different instruments to list or group the words) and metacognitive (self-evaluation or testing the vocabulary knowledge).On the other hand, Nation (2001) separated the process into three groups such as planning (deciding how, when, where to use the word), source (getting knowledge about the word and its basis), and process (deciding the way to learn the word).

Inferring from context is also another vocabulary learning strategy, and simply leads the L2 learners to incidental learning, to derive meaning from the context and to hesitate using the bilingual dictionary.In spite of its positive effect on vocabulary learning, some controversial arguments (as Sökmen (1997) mentioned) submit that inferring is a time consuming process (Sternberg, 1987), learners are more disposed for misestimating (Kelly, 1990), the individual differences such as working memory and lack of explicit knowledge encourage incorrect prediction (Haynes \& Baker, 1993), too much stress on the inferring attainment leave no alternative skills to allow the learners complete the metacognitive stage, and finally, ineffectiveness leads the deficit needs arise such as permanence (Mondria \&Wit de-Boer, 1991; Wesche \& Paribakht, 2010).

From the extensive perspective of technological improvements, variety of media materials such as videos, audial and visual contents catch the learners with relative ease (Kim \& Gilman, 2008). Nowadays, online learning becomes very popular at Turkish universities, which also enables the learners to attend in distance education. In addition to word memorization, creating word lists, memorizing pair associations or using bilingual dictionaries, new strategies about vocabulary learning such as hearing the pronunciation of a word, a clear image or both visual and audial materials, rich in content, are more helpful for L2 learners (Meara, 1996, Al-Seghayer, 2005, Ehsani \& Knodt, 1998,Koroghlanian \& Klein, 2004;Kost, Foss, and Lenzini, 1999). Technological developments initiate new trends in vocabulary learning such as cognitive load theory (Sweller, Van Merrienboer, \& Paas, 1998), and constructivist learning theory (Novak, 1998, Vygotsky, 1978) and a cognitive theory of multimedia learning(Mayer \& Moreno, 2003). The mentioned studies give way to reach interesting results (as Mayer and Moreno, 2003, touched before) such as L2 learners performed better when narration and animation were approached together, when minimising the number of unnecessary words, or in different learning environments, the learners are more successful when pictures are added (Tindall-Ford, Chandler \& Sweller, 1997), inferring from the context provide the learners to find the solution by themselves rather than obtaining it directly (Grace, 1998), or inferring increases the self-reliance of the learners (Prince, 1996). However, according to age, individual differences or context, and some of the materials such as pictures, non-audial videos or graphics can influence the learners' attention and change their perception negatively. Some of the previous studies have shown that inferring from the context does not affect the learners' performances positively (Coady, 1993; Qian, 1996). Likewise, the reasons for ineffectiveness of context learning have been investigated from various perspectives such as specific words and contextual clues (Harley, Howard \& Roberge, 1996).

\section{The Method}

\subsection{The Purpose of the Study}

The aim of the study is to find out whether movies (as visual and audial context) have any effect on vocabulary learning or not. Thus, the research questions of the study are as follows;

1. Is vocabulary learning more effective by watching movies than traditional methods as measured by L2 learners' post-test results?

2. Are the words learned by movies like movies more permanent than the ones learned by traditional methods? 


\subsection{Participants}

The participants were 30 Turkish adult L2 learners of English (intermediate level) aged from 21 to 25. None of the participants were informed the ultimate goal of this study. Each participant was required to fulfil a pre-test, post-test and the second post-test after two months from the experiment for this study.

\subsection{Instruments}

Initially, the language background test and English proficiency test were administered to the participants in order to state homogenous groups, then before the experiment, the participants were divided into two groups: the control and the experimental, and both of them were intermediate level. Pre-test was conducted to the participants, and after the experiment, post-test was given. Two months later, the participants were reassessed with the posttest 2 again in order to see which strategy is more effective on retaining. The scores for pre-and-post tests were checked according to correct answers (each correct answer was rated for 2, and the incorrect ones were rated for 1).

\subsection{Procedure}

On the first day of the experiment, the participants were informed briefly about what they are requested to do through the experiment. After they filled the background task and proficiency test, they were required to respond the pre-test which is comprised of 20 experimental question sentences and 40 fillers (the fillers were selected from all grammatical subjects in order not to reveal the main purpose of the experiment) in regarding to understand whether the participants knew the meaning of the experimental words used in this study. Then, they were randomly assigned into two groups. The control group practices the vocabularies in traditional strategies such as note taking, bilingual dictionaries and word lists, on the other hand, the experimental group practices the visual context such as the English movie "The King's Speech". The trial lasted for 6 weeks in 6 sessions to both groups. The movieis supported by English subtitles of the conversations, and no other cue was given on the screen. The reason why "The King's Speech" has been decided was that thepronunciation of the words wasclear, and there were not much proverbs or idiomsin the characters' cues.

On the last day of the experiment, both groups were instructed to answer the post-test, and the scores obtained from pre-and-post tests were statistically analysed in order to find out whether there was any significant difference between the control and experimental groups.

\subsection{Data analysis}

The obtained data were evaluated according to SPSS statistic program (by using t-test). Each correct item was scored as 2, and the incorrect answers were 1. Pre-and-post tests were used to examine how accurate the participants infer and remember the meaning of the target words. The experimental group practiced the vocabulary sessions with a projector reflected by the teacher's computer, and heard the pronunciation of the words from the native speakers in a dialogue, during the movie "The King's Speech", however, the control group practiced the vocabulary sessions in pen-and-paper environment, and heard the pronunciation of the words from the non-native speakers.

\section{Results}

Pre-and-post test results were analysed in SPSS statistical analysing software by using independent t-test sample to establish whether there is any difference between the two participant groups (sig. level: 0.05).

\begin{tabular}{|l|l|l|l|l|l|}
\hline \multicolumn{7}{|c|}{ Table 1: Mean Scores of the Groups } \\
\hline \multirow{3}{*}{ Pre-test } & groups & N & Mean & Std. Deviation & Std. Error Mean \\
\cline { 2 - 7 } & Control & 15 & 3,0000 & 1,06904 &, 27603 \\
\cline { 2 - 6 } & Experimental & 15 & 2,0000 & 1,13389 &, 29277 \\
\hline Post-test & Ccontrol & 15 & 8,6000 & 1,35225 &, 34915 \\
\cline { 2 - 6 } & Experimental & 15 & 14,6000 & 1,50238 &, 38791 \\
\hline Post-test2 & Control & 15 & 7,0000 & 1,41421 &, 36515 \\
\cline { 2 - 6 } & Experimental & 15 & 12,7333 & 1,16292 &, 30026 \\
\hline
\end{tabular}


As can been seen from the table 1, the control and the experimental groups included 15 participants equally. In pre-test, the control group scored 3 correct answers and the experimental group scored 2 correct answers, and according to the post-test, the experimental group (14 correct answers of 20 questions) performed better than the control group (8,6 correct answers of 20 questions). Similarly, in the post-test 2 , in which the participants were conducted the same questions of the post-test again after two months for revealing whether the vocabulary were for long-term or not, the results have shown that the experimental group performed better in recalling the information than the other.

Figure 1: Mean Scores in Pre-Test, Post-Test and Post-Test2

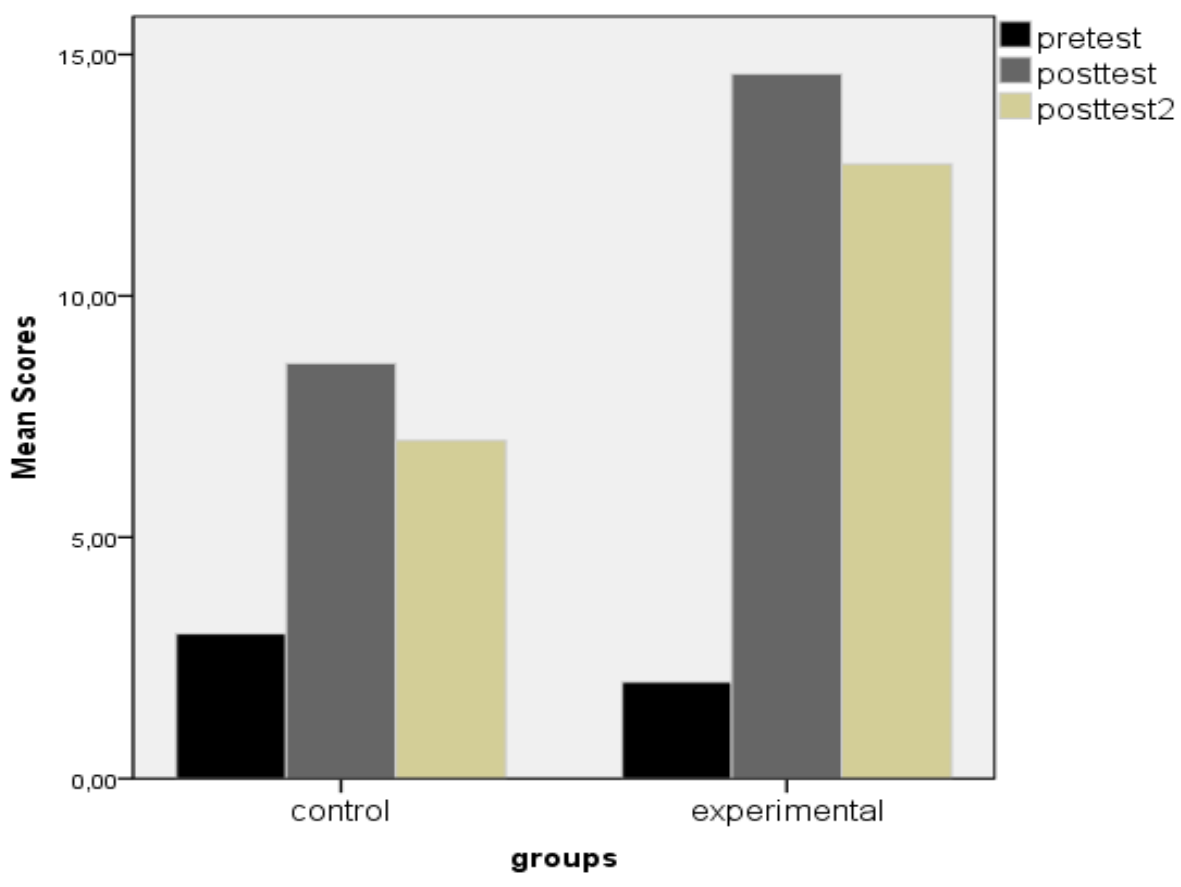

The pre-test results indicated that there was not any significant difference between groups $(t=2,485, \mathrm{df}=28, \mathrm{p}=0$, $19>0.05)$. On the other hand, the t-test statistical analysis demonstrated that there is a significant difference in the post-test $(\mathrm{t}=-11,496, \mathrm{df}=28, \mathrm{p}=0,00<0,05)$ and post-test $2(\mathrm{t}=-12,128, \mathrm{df}=28, \mathrm{p}=0,00<0,05)$ between two participant groups. These results showed that the experimental group who received visual context, earned significantly higher scores than the control group who experienced traditional vocabulary learning strategies. Similarly, from the retention test (post-test2), the t-test data also revealed that there was statistically difference between groups which indicated that the participants who learned and retain English vocabulary more effectively with visual context, movie or videos.

\section{Discussion and Conclusion}

The purpose of this study is to examine vocabulary learning strategies whether there is any difference between traditional strategies and inferring from visual context. The findings from this study indicate that learning L2 English vocabulary from the visual context which is presented with an English movie, "The King's Speech", is easier for adult Turkish L2 learners of English than the traditional vocabulary learning strategies such as note taking, word lists or repetition. The vocabulary information based on visual context or movie, helped the participants to learn and retain more effectively than the other strategies showed in the pre-and-post tests. The probable reason is that vocabularies are not usually translated or taught explicitly (by giving meaning), but visualized in a more meaningful way, in visual contexts. Some words cannot be translated into another language, for example, when the learners get the information in a visual context such as "petition" from the movie "The King's Speech", means "letter", may not let the learners the exact meaning and allow them to think about what kind of letter instead of vocabulary itself, however, a visual context in which, for instance, in a scene(the king sends a petition to the congress) is much more effective on learning and retaining according to the results of the present study, which is compatible with the previous studies (Sadoski \& Paivio, 2001; Mayer \& Moreno, 2002; 
Sun \& Dong, 2014; Nelson, 1998; Spiri, 2008; Aydın Yıldı, 2017; Karakaş \& Saricoban, 2012; Yuksel \& Tanriverdi, 2009).

Furthermore, the participants had the chance to have fun and overview from visual and audial materials during learning vocabulary, rather than memorizing, repetition or writing vocabulary lists. Learning vocabulary from the visual contest like movies or videos, help the learners to individualize and experience the language by using metacognitive abilities such as self-assessment, as mentioned in the study of Schmitt (1997). Also, they learn how to use videos or movies as a vocabulary learning tool in their daily life (Atay \& Ozbulgan, 2007).

Retaining in the experimental group is better than the control group, as the former remembered the words and performed better scores in the second post-test which is in alignment with some of the previous studies (Koren, 1999; Rott, Williams \& Cameron, 2002), asserting that explicit vocabulary learning, for example giving the translation of the unknown word, discourages inferring from the context.

Some aspects of the experiment are universal for learners from different ages such as inferring the meanings from visual contexts allow the learners to be more active and intentional, since in this study, the adult learners managed the vocabulary learning process more effectively so did the children in the study of (Dong, 2001). The results of the present study are in the same line with some of the previous studies resulting that videos as vocabulary learning materials support the language proficiency (Bird \& Williams, 2002, Danan, 2004; Neuman \& Koskinen, 1992).

\section{References}

Al-Seghayer, K. (2005). The effects of verbal and spatial abilities on reading comprehension task performance in multimedia environments with respect to individual differences among learners. CALL-EJ Online, 7(1).

Atay, D., \& Ozbulgan, C. (2007). Memory strategy instruction, contextual learning and ESP vocabulary recall. English for Specific Purposes, 26, 39-51

Aydin Yildiz, T. (2017). The Effect of Videos with Subtitles on Vocabulary Learning of EFL Learners. International Journal of Humanities and Social Science, 7(9), 125-130. (Press No: 4182853)

Bird, S. \& Williams, J. N. (2002). The effect of bimodal input on implicit and explicit memory: An investigation of within-language subtitling. Applied Psycholinguistics, 23, 4, 509-533.

Canning-Wilson, C. (2000). Practical Aspects of Using Video in the Foreign Language Classroom. http://iteslj.org/Articles/Canning- Video.html

Coady, J. (1993). Research on ESL/EFL vocabulary acquisition: Putting it in context. In T. Huckin, M. Haynes, \& J. Coady (Eds.), Second language reading and vocabulary learning (pp. 3-23). Norwood, NJ: Ablex Publishing.

Danan, M. (2004). Captioning and subtitling: undervalued language learning strategies. Meta: Translators' Journal, 49(1), 67-77.

Dong, Y. (2001). Direct and indirect L2 vocabulary learning in the communicative approach. Foreign Language Teaching and Research, 33(3), 186-192.

Ehsani, F., \& Knodt, E. (1998). Speech technology in computer-aided language learning: strengths and limitations of a new CALL paradigm. Language Learning and Technology 2,(1) 45-60. Retrieved May 2, 2000 from the World Wide Web: http://lit.msu.edu/vol2num1/article3/index.htm

Harley, B., Howard, J., \& Roberge, B. (1996). Teaching vocabulary: An exploratory study of direct techniques. Canadian Modern Language Review, 53, 281-304

Hatch, E., \& Brown, C. (1995). Vocabulary, semantics, and language education, Cambridge: Cambridge University Press.

Haynes, M., \& Baker, I. (1993). American and Chinese readers learning from lexical familiarization in English texts. In T. Huckin, M. Haynes, \& J. Coady (Eds.), Second language reading and vocabulary learning (pp. 130-152). Norwood, NJ: Ablex.

Ghazal, L. (2007). Learning vocabulary in EFL contexts through vocabulary learning strategies. NovitasRoyal, 1(2), 84-91.

Grace, C. (1998). Retention of word meanings inferred from context and sentence-level translations: Implications for the design of beginning-level CALL software. The Modern Language Journal, 82, 533-544.

Gu, Y., \& Johnson, R. K. (1996). Vocabulary learning strategies and language learning outcomes. Language Learning 46 (4), $643-79$. 
Karakaş, A., \& Sariçoban, A. (2102). The impact of watching subtitled animated cartoons on incidental vocabulary learning of ELT students. Teaching English with Technology, 12 (4). 315.

Kelly, P. (1990). Guessing: No substitute for systematic learning of lexis. System, 18, 199207.

Kim, D., \& Gilman, D. A. (2008). Effects of Text, Audio, and Graphic Aids in Multimedia Instruction for Vocabulary Learning. Educational Technology \& Society, 11 (3), 114- 126.

Koren, S. (1999). Vocabulary instruction through hypertext: Are there advantages over conventional methods of teaching? TESL-EJ, 4(1), 1-18. Retrieved March 29, 2009, from http://tesl-ej.org/ej13/a2.html.

Koroghlanian, C.M. \& Klein, J. D. (2004). The effect of audio and animation in multimedia instruction. Journal of Educational Multimedia and Hypermedia, 13, 23-46.

Kost, C. R., Foss, P., \& Lenzini, J. J. (1999). Textual and pictorial glosses: Effectiveness of incidental vocabulary growth when reading in a foreign language. Foreign Language Annals, 32(1), 89-113.

Nation, P. (1990). Teaching and learning vocabulary. New York: Newbury House.

Nation, P. (2001). Learning vocabulary in another language. Cambridge: Cambridge University Press.

Neuman, S. B. \& Koskinen, P. (1992). Captioned television as comprehensible input: effects of incidental word learning from context for language minority students. Reading Research Quarterly, 27, 1, 95-106.

Mayer, R. E., \& Moreno, R. (2003). Nine ways to reduce cognitive load in multimedia learning. Educational Psychologist, 38, 43-52.

Meara, P. (1996). The dimensions of lexical competence. In Brown, G., Malmkjær, K., Williams, J. (eds) Performance and Competence in Second Language Acquisition. Cambridge: Cambridge University Press, 35-52.

Mondria, J.A., \& M. Wit-de Boer. (1991). "The effects of contextual richness on the guessability and the retention of words in a foreign language", in Applied Linguistics, 12, 249-67.

Morin, R. \& Goebel, J. (2001). Basic vocabulary instruction teaching strategies or word? Foreign Language Annals, 34 (1), -16 .

Nelson, B. (1998). Web-based vocabulary activities: pedagogy and practice. Computer Assisted Language Learning, 11(4), 427-435.

Novak, J. D. (1998). Learning, Creating, and Using Knowledge: Concept Maps as Facilitative tools in Schools and Corporations. Mahwah, NJ: Lawrence Erlbaum \& Associates. Spanish, 1998, Madrid: Alianza Editorial. Portuguese, 2000, Lisboa: Platano Edicoes Tecnicas. Italian, 2001, Trento: Edizioni Erickson. Finnish, 2003, Jyuvaskyla, Finland: PS-kustannus.

Oxford, R. (1990). Language learning strategies: What every teacher should know. New York: Newbury House.

Prince, P. (1996). Second Language vocabulary learning: The role of context versus translations as a function of proficiency. The Modern Language Journal, 80, 478-493.

Qian, D.D. (1996). ESL vocabulary acquisition: Contexualization and decontextualization. Canadian Modern Language Review, 53, 120-142.

Richards, J. C. (1976). The role of vocabulary teaching. TESOL Quarterly, 10 (1), 77.

Rott, S., Williams, J., \& Cameron, R. (2002). The effect of multiple-choice L1 glosses and inputoutput cycles on lexical acquisition and retention. Language Teaching Research, 6, 183- 222.

Ryan, A. (1997). Learning the orthographical form of L2 vocabulary-a receptive and a productive process. In N. Schmitt \& M. McCarthy (Eds.), Vocabulary: Description, acquisition and pedagogy (pp. 181-198). Cambridge: Cambridge University Press.

Sadoski, M., \& Paivio, A. (2001). Imagery and text: A dual coding theory of reading and writing. Mahwah, NJ: Lawrence Erlbaum Associates.

Schmitt, N. (1997). Vocabulary learning strategies. In N. Schmitt \& M. McCarthy (Eds.),Vocabulary: description, acquisition and pedagogy (pp.199-228). Cambridge: Cambridge University Press.

Seal, B. D. (1991). Vocabulary learning and teaching. In M. Celci- Murcia (Ed.), Teaching English as a second or foreign language. Boston, MA: Heinle \& Heinle.

Sokmen, A.J. (1997). Current trends in teaching second language vocabulary. In N. Schmitt \&M. McCarthy (Eds.),Vocabulary: Description, acquisition and pedagogy (pp.237-58). Cambridge: Cambridge University Press.

Sternberg, R. J. (1987). Most vocabulary is learned from context. In M. G. McKeown, \& M. E. Curtis (Eds.), The nature of vocabulary acquisition (pp. 89-105). Hillsdale, NJ: Erlbaum. 
Sun, Y., Dong, Q. (2014).An experiement on supporting children's English vocabulary learning in multimedia context.Computer Assisted Language Learning, 17(2), 131-147.

Sweller, J., van Merriënboer, J. J. G., \& Paas, F. (1998). Cognitive architecture and instructional design. Educational Psychology Review, 10, 251-296.

Tindall-Ford, S. \& Sweller, J. (2006). Altering the modality of instructions to facilitate imagination: Interactions between the modality and imagination technique. Journal of Experimental Psychology: Applied, 34, 343365.

Vygotsky, L. S. (1978). Mind in Society: the Development of Higher Psychological Processes. Cambridge, MA: Harvard University Press.

Wesche, M., Paribakht, T.S. (2010). Lexical inferencing in a first and second language: Crosslinguistic dimensions, Clevedon, UK: Multilingual Matters

Weyer, J. R. (1999). The effect of authentic video on communicative competence. The Modern Language Journal, 83, 3, 339-349.

Yüksel, D. \& Tanrıverdi, B. (2009). Effects of watching captioned movie clip on vocabulary development of EFL learners. The Turkish Online Journal of Educational Technology, 8(2), 48-54.

\section{Appendix A}

\section{The Experimental Vocabularies from the Movie "The King's Speech"}

1. Abdicate

2. Defecation

3. elocution

4. petition

5. shack

6. guts

7. biplane

8. sieve

9. ribs

10. bounces

11. jaw

12. devilish

13. sublime

14. shilling

15. wager

16. stammer

17. take a stroll

18. brows

19. turf

20. Larynx 